\title{
Decisiones de inversión y rentabilidad bajo la valoración financiera en las empresas industriales grandes de la provincia de Cotopaxi, Ecuador
}

\author{
Erika Cristina Caiza Pastuña*
} Edison Roberto Valencia Nuñez ${ }^{* *}$ Mayra Patricia Bedoya Jara***

Fecha de recibido: 19 de agosto de 2019 Fecha de aprobado: 2 de diciembre de 2019

Para citar este artículo: Caiza Pastuña, E. C., Valencia Nuñez, E. R., \& Bedoya Jara, M. P. (2020). Decisiones de inversión y rentabilidad bajo la valoración financiera en las empresas industriales grandes de la provincia de Cotopaxi, Ecuador. Revista Universidad E Empresa, 22(39), 1-29. https://doi.oirg/10.12804/revistas.urosario.edu. co/empresa/a.8099

Asesor financiero en Banco Solidario. Obtuvo una maestría en Finanzas mención dirección financiera en la Universidad Técnica de Ambato y una ingeniería en Finanzas y Auditoria-CPA en la Universidad de las Fuerzas Armadas ESPE- Latacunga. Actualmente es asesora educativa y financiera independiente, desarrollando proyectos financieros y contables. Correo electrónico: eri_ka1992@hotmail.com

** Máster en Estadística, y Matemáticas, Docente Investigador de la Universidad Técnica de Ambato. Correo electrónico: edisonrvalencia@uta.edu.ec

*** Doctora en Contabilidad, Docente Investigador de la Universidad Técnica de Ambato. Correo electrónico: mp.bedoya@ uta.edu.ec 


\title{
Resumen
}

Actualmente no existe un estudio enfocado en las decisiones de inversión y la rentabilidad bajo el modelo de valoración de activos de capital de las empresas industriales más grandes de la provincia de Cotopaxi. En tal sentido, el presente estudio ha determinado tres objetivos fundamentales: evaluar las decisiones de inversión a largo plazo a través de la valoración financiera, medir los niveles de rentabilidad a través de la aplicación del modelo de valoración de activos de capital y relacionar la rentabilidad y su efecto en las decisiones de inversión a través de técnicas estadísticas. A partir de una muestra de cinco empresas, las más grandes de la provincia de Cotopaxi, y mediante la aplicación del modelo de valoración de activos de capital (CApm) se analizaron las hipótesis. Se confirmó a través del estadístico de Wilcoxon la relación directa de la rentabilidad y su efecto en las decisiones de inversión, se estableció que el rendimiento sobre el patrimonio, las ventas y la rentabilidad financiera presentan una tendencia a crecer a partir del año 2016, producto de la correcta gestión financiera en inventarios, proveedores y cartera de crédito; esta condición hace al sector industrial atractivo para invertir.

Palabras claves: decisiones de inversión; rentabilidad; valoración financiera.

\section{Investment Decisions and Profitability under the Financial Valuation in the Large Industrial Companies of the Cotopaxi province, Ecuador}

\begin{abstract}
Currently, there is no study focused on investment decisions and profitability under the valuation model of capital assets of the largest industrial companies in the province of Cotopaxi. In this regard, the present study has identified three fundamental objectives: evaluate long-term investment decisions through financial valuation, measure profitability levels through the application of the capital asset valuation model, and relate profitability and its effect on investment decisions through statistical techniques. Based on a sample of five companies, the largest in the province of Cotopaxi, and through the application of the capital asset valuation model (CAPM), the hypotheses were analyzed. The direct relationship of profitability and its effect on investment decisions was confirmed through the Wilcoxon statistician, it is established that the return on equity, sales, and financial profitability showed a tendency to grow as of 2016, product of the correct financial management in inventories, suppliers, and the credit portfolio, this condition makes the industrial sector attractive to invest.
\end{abstract}

Keywords: investment decisions; profitability; financial valuation.

\section{Decisões de investimento e rentabilidade sob a valoração financeira nas empresas industriais grandes da província de Cotopaxi, Equador}

\section{Resumo}

Atualmente não existe um estudo focado às decisões de investimento e a rentabilidade sob o modelo de valoração de ativos de capital das maiores empresas industriais da província de Cotopaxi. Neste sentido o presente estudo tem determinado três objetivos fundamentais: avaliar as decisões de investimento a longo prazo através da valoração financeira, medir os níveis de rentabilidade através da aplicação do modelo de valoração de ativos de capital, relacionar a rentabilidade e seu efeito nas decisões de investimento através de técnicas estatísticas. Baseado em uma amostra de cinco empresas consideradas as maiores da província de Cotopaxi e mediante a aplicação do modelo de valoração de ativos de capital (CAPM), analisaram-se as hipóteses. Confirmou-se através do estatístico de Wilcoxon a relação direta da rentabilidade e seu efeito nas decisões de investimento, se estabelece que o rendimento sobre o patrimônio, as vendas, e a rentabilidade financeira apresentou uma tendência a crescer a partir do ano 2016, produto da correta gestão financeira em inventários, fornecedores e carteira de crédito, esta condição faz ao setor industrial atrativo para investir.

Palavras-clave: decisões de investimento; rentabilidade; valoração financeira. 


\section{Introducción}

El sector industrial se constituye como un eje central para la economía y el desarrollo social de cualquier país, ya que cumple un rol determinante en la innovación tecnológica, la investigación y el desarrollo de actividades. El proceso de industrialización mundial pone en evidencia que América Latina y el Caribe no cuentan con capacidad competitiva industrial para hacer frente a otras regiones del mundo, como es el caso de los países de Asia del Este (Horna, Guachamín \& Osorio, 2009). De acuerdo a Rivera (2013), la industrialización en América Latina fue un proceso estrechamente vinculado a la sustitución de importaciones, que se dio por la crisis económica de 1929 y la Segunda Guerra Mundial. A principios de los 80, la economía mundial entró en un período de inflación originada principalmente por el alza de los precios del petróleo que obligó a los países desarrollados a implementar políticas contraccionistas: restricción del crédito y aumento de las tasa de interés. La participación de las manufacturas en el PIB venía creciendo lentamente en los 60 y 70, pero al finalizar los 80 descendió. En 1996, Brasil solo aportaba el 37.3\% del PIB manufacturero del total latinoamericano. Las tres economías más importantes (Brasil, México y Argentina) aportaban el 80\% y Perú, Venezuela, Colombia y Chile, el 16\%.

El sector industrial en una nación es una parte esencial en su economía, debido a que trabaja como un significativo multiplicador de las actividades relacionadas, ya sea como demandante de recursos y mano de obra, y estimula resultados en la economía (Pabón, 2015). Ecuador está catalogado como un país en vías de desarrollo por el poco impulso que se les ha dado a las ramas manufactureras y a la falta de una adecuada valoración financiera. Por tal motivo, son pocas las industrias que presentan grandes avances, a pesar de que su desempeño es significativo para la economía (Horna, Guachamín \& Osorio, 2009).

Según Costa de García (2018) : "El desarrollo de este sector fortalece al país, ya que más allá genera fuentes de empleo calificadas y formales. De acuerdo al INEC, a septiembre de 2017 esta actividad generó el 11\% del empleo total del país" (p. 10). En los últimos años, Ecuador ha transformado y extendido su cadena productiva hacia nuevos mercados internacionales lo que le ha permitido desarrollar la producción en serie de artículos destinados principalmente a satisfacer necesidades del consumidor (Instituto Nacional de Estadistica y Censo, 2018). En la provincia de Cotopaxi, la principal actividad de manufactura, en el 
primer puesto del ranking, es de la rama metalmecánica, más específicamente la fabricación de tubos, caños y perfiles huecos (fundidos, soldados o remachados) y acero hueco para minas. La segunda actividad principal de manufactura en esta provincia es la producción de papel, específicamente la fabricación de pañuelos, pañuelitos faciales, papel higiénico, toallas, servilletas, pañales y forros de pañales para bebés, tampones, toallas higiénicas, etc. (Guaman \& Bravo, 2014). Lo que se evidencia es que la provincia enfoca su fuerza industrial en productos utilizados para la construcción. Sin embargo, las empresas experimenten cambios como resaltan Sierra y López (2014): "deben cobijar políticas financieras, dentro de las que se destacan las de inversión o de activos" (p. 71). Del mismo modo se puede constatar que las industrias han ido incluyendo planes estratégicos con el objetivo de generar desarrollo en todo lo referente a la operación de la empresa (Lizarzaburu \& del Brio, 2016). Producto de los grandes cambios que se han venido dando en el sector, el entorno de las empresas y los gerentes y administradores desafían la necesidad de nuevos conocimientos de alto nivel que les permitan tomar decisiones claves y oportunas, lo cual requiere la utilización de herramientas y estrategias útiles como modelos matemáticos, pronósticos, análisis para manejar eficientemente los recursos y alcanzar los objetivos planteados en su filosofía empresarial (Betancourt, García \& Lozano, 2013).

En este trabajo se valúa la opción de seleccionar un proyecto de inversión si la capacidad de la empresa genera los flujos de efectivo suficientes para concluir el proyecto, puesto que por lo general, al momento de invertir de acuerdo a lo que menciona Romero y Barrientos (2013) "se hacen el siguiente cuestionamiento: ¿Cómo debo conformar mis portafolios? Es decir, ¿cuál es la combinación óptima de activos disponibles que permita maximizar la rentabilidad esperada, pero a la vez exponerse a mínimo riesgo de pérdida?” (p. 71). Para ello, se considera una base de datos histórica de los principales estados financieros de las cinco empresas industriales más representativas de la provincia de Cotopaxi, donde se realiza una proyección con un horizonte a 5 años de los estados financieros para conocer qué tan sostenible es la empresa en el tiempo, se incorpora la probabilidad de pasar de un cierto nivel de flujos de efectivo a otro a futuro y se incorpora la volatilidad histórica de estos, con el fin de valorar financieramente las empresas y estimar un valor que permita determinar qué tan rentable es para el accionista. Así, surge la necesidad de establecer un modelo de valoración que exponga de forma significativa la información de las rentabilidades (García, 2005). 
El objetivo de este trabajo es medir la relación de la rentabilidad con las decisiones de inversión bajo el modelo CAPM, puesto que este permite comprobar "la validez del modelo en el ámbito de las decisiones de presupuestación de capital" (Muhammad \& Mohsin, 2015, p. 61). En este caso, valorando financieramente las empresas del sector industrial/ manufacturero de la provincia de Cotopaxi y considerando que el proceso de toma de decisiones de inversión constituye una actividad a la que comúnmente se enfrentan inversionistas que desean incrementar su capital financiero mediante la adquisición o compra de partes del capital social de una empresa constituida. "Teóricamente, en un mercado racional el portafolio de mercado debería reflejar características de la relación rentabilidad-riesgo consistentes con una frontera eficiente que la optimiza" (Contreras, Bronfman \& Arenas, 2015, p. 384). Por otro lado, la negociación de activos con un estudio exhaustivo de diferentes carteras de inversión da paso a que los riesgos relacionados a la economía de mercado los resistan solo quienes estén más preparados para hacerlo (Garrison, 2012).

Para los fines del presente trabajo, el documento se organiza de la siguiente forma. A continuación, se presenta la revisión de la literatura relacionada con las metodologías de toma de decisiones de inversión y rentabilidad, en la siguiente sección se describe un comparativo entre las condiciones económicas que presenta el sector en estudio. Después, se describe la dinámica financiera de cada empresa del sector industrial de la provincia de Cotopaxi. Asimismo, se desarrolla el modelo CAPM y la valoración financiera por cada empresa.

\section{Metodología}

\subsection{Revisión de la literatura}

\subsubsection{Modelo CAPM}

En la metodología propuesta, se utiliza el modelo CAPM, conocido como modelo de valoración de activos de capital, que es "el mejor esquema para cubrirse del riesgo en el mercado accionario" (Londoño \& Yaneth, 2011, p. 63), y describe formalmente la relación entre el riesgo y el rendimiento. También sirve como un marco general para comprender 
el riesgo sistemático, la diversificación y la prima de riesgo sobre la tasa libre de riesgo que es necesaria para atraer capital (Cervantes, Villalba \& Carmona, 2013).

La fórmula es la siguiente:

$C A M P=R f+\beta(R m-R f)$

Donde:

$\mathbf{R f}=$ Tasa de interés libre de riesgo

$\boldsymbol{\beta}=$ Beta de riesgo

$\mathbf{R M}=$ Rendimiento del mercado

De acuerdo con Santibañez, Alcañiz y Gómez (2014), «una conocida medida de riesgo "relevante" de un activo es: la beta, medida del riesgo que no puede eliminarse por diversificación» (p. 331). Asimismo, la beta puede ser interpretada como la respuesta de la variabilidad de rendimientos de una acción (Martínez, Ledesma \& Russo, 2013).

Murillo, Peña y León (2017) señalan que un activo se considera libre de riesgo cuando su retorno se iguala al retorno esperado; por consiguiente, la tasa libre de riesgo pertenecería a la tasa de retorno del activo libre de riesgo. En definitiva, el CAPM explica satisfactoriamente el comportamiento del mercado bursátil (Contreras \& Cartes, 2012).

Según Veloz (2015) el modelo tiene las siguientes características:

- La rentabilidad presenta una relación proporcional directa con el riesgo, ya que a mayor riesgo se obtendrá una mayor rentabilidad.

- La versatilidad en el precio de una acción, el riesgo, es de tipo sistemático y no sistemático. El primero se refiere al riesgo del mercado, asociado a cambios económicos provocados por factores externos e internos. El segundo, trata sobre factores internos o propios de la firma sin que se vean afectados por aspectos económicos (Velez, 2003). 
De igual forma, otro supuesto en el que se basa el CAPM, mencionado por Guerrero (2008), es que las cantidades disponibles de los diferentes activos financieros con riesgo se hallan fijadas como una variable exógena del modelo; en otras palabras, la oferta de los activos financieros está dada. Por otro lado, "la utilidad del modelo radica en la posibilidad de estimar el costo de capital al momento de realizar valoraciones de empresas, por el método de flujo de caja descontado, o al hacer evaluación de proyectos de inversión nuevos" (Viloria, 2015, p. 91).

El riesgo sistemático es la variación en el precio de la acción por causas exclusivas de cada empresa, el cual puede suprimirse diversificando el portafolio de activos financieros. Además, "la beta del CAPM tradicional explica el 36\% de las variaciones en la rentabilidad de los mercados emergentes" (Marcelo, Quirós \& Quirós, 2007a). Por otro lado, Marcelo, Quirós y Quirós (2007b) añaden que, de acuerdo con el CAPM, "el exceso de rentabilidad esperada de un activo es proporcional a su beta de mercado, que es constante a lo largo de periodos de elevada y reducida rentabilidad de mercado" (p. 795).

La metodología que adoptan algunas empresas son útiles para evaluar o en tal caso clasificar las opciones de inversión que son viables (Canales, 2015). Por consiguiente, aparte del modelo expuesto anteriormente se hace un análisis por empresa de la rentabilidad para lo cual se plantean varios indicadores (Gallardo, 2012).

Tabla 1. Clasificación de la rentabilidad

\begin{tabular}{lcll}
\hline \multicolumn{1}{c}{ Clase } & Ecuación & & \multicolumn{1}{c}{ Interpretación } \\
\hline Rentabilidad bruta sobre ventas & $\frac{\text { Utilidad bruta }}{\text { Ventas }}$ & Mide el palanqueo financiero a corto plazo. \\
\hline Rentabilidad neta sobre ventas & Util. Neta después de imp. & $\begin{array}{l}\text { Determina el margen de utilidad obtenido } \\
\text { luego de deducir las ventas de todos los costos } \\
\text { yen gastos. }\end{array}$ \\
\cline { 2 - 3 } Rendimiento sobre el patrimonio & $\frac{\text { Util. Neta después de imp. }}{\text { Patrimonio neto }}$ & $\begin{array}{l}\text { Mas conocido como ROE mide el retorno del } \\
\text { capital del accionista. }\end{array}$ \\
\hline Rendimiento sobre el activo total & Utilidad neta & $\begin{array}{l}\text { ROA determina la productividad o rentabilidad } \\
\text { de las ventas como resultado del empleo de } \\
\text { los activos. }\end{array}$ \\
\hline
\end{tabular}

Fuente: Gallardo (2012). 
En términos generales la rentabilidad trata de medir el modo en que la empresa es capaz de generar un superávit para repartirlo a los accionistas, que se puede comparar con los recursos totales invertidos en la actividad, como medida de la eficiencia lograda. De acuerdo con Izquierdo (2016), "las empresas más rentables son las que más crecen, debido a su capacidad para generar beneficios" (p. 281). La rentabilidad mide el rendimiento de los activos de la empresa como el de los recursos aportados por los accionistas y proporciona alguna indicación del grado de éxito en el logro de crear riqueza para sus propietarios (Puerta, Vergara \& Huertas, 2018). Desde el punto de vista contable, el estudio y análisis de la rentabilidad se realiza en dos niveles.

\subsubsection{Rentabilidad económica}

La rentabilidad económica o de la inversión es una medida del rendimiento de los activos de una empresa con independencia de su financiación, dado en un determinado periodo. Así, esta se constituye como un indicador básico para juzgar la eficiencia empresarial, pues al no considerar las implicancias de financiamiento es posible ver qué tan eficiente o viable ha resultado en el ámbito del desarrollo de su actividad económica o gestión productiva (Ccaccya, 2015, p. 2). Asimismo, si se permite que agentes económicos tengan una consideración dinámica del riesgo conectada al momento económico, se admitiría la posibilidad de que la rentabilidad que se espera varíe a lo largo del tiempo (Marcelo, Quirós \& Quirós, 2013).

\subsubsection{Rentabilidad financiera}

Es una medida referida a un determinado periodo del rendimiento obtenido por los capitales propios, generalmente con independencia de la distribución del resultado. La rentabilidad financiera puede considerarse así una medida de rentabilidad más cercana a los accionistas o propietarios que la rentabilidad económica, y de ahí que teóricamente, y según la opinión más extendida, sea el indicador de rentabilidad que los directivos buscan maximizar en interés de los propietarios (Ccaccya, 2015, p. 2).

Por ello, las decisiones estratégicas de inversión son actividades cruciales para el desarrollo de una organización. Los proyectos de inversión se encuentran expuestos a diversos tipos de riesgo: financiero, político y de mercado, entre otros. Aunque se pueden mencionar varios tipos de metodologías de medición que intentan incluir el riesgo en la valoración 
de proyectos, la mayoría de ellas tiene falencias, que pueden ser abordadas para dar lugar a mejores indicadores de bondad económica y financiera (Manotas \& Toro, 2009, p. 199). La toma de decisiones es la selección de un curso de acción entre varias opciones; un aspecto fundamental en la toma de decisiones es la percepción de la situación por parte de la empresa implicada (Herrera, 2014). Existen dos tipos de decisiones fundamentales, las decisiones programadas y las decisiones no programadas.

\subsubsection{Decisiones programadas}

Los gerentes o administradores se basan en resultados pasados, circunstancias presentes y expectativas cuando toman decisiones; deducen que las decisiones se toman según el problema. Así, estas son unas decisiones repetidas que se manejan de rutina (Gallardo et al., 2010, p. 213)

\subsubsection{Decisiones no programadas}

Las decisiones no programadas son aquellas que son únicas, no se repiten y requieren soluciones a la medida; es decir, son las que toman los gerentes frente a problemas nuevos o inusitados y para los cuales la información es incompleta. Son decisiones nuevas y no repetitivas basadas en juicios, tomadas para solucionar problemas no rutinarios o excepcionales (Gallardo, 2012, p. 214).

\section{Resultados}

\subsection{Condiciones económicas del sector}

Las compañías del sector industrial alimenticio de la provincia de Cotopaxi reflejan un decremento dentro del periodo de estudio, en el año 2015 había 15 empresas y en el año 2017,14 . Para el sector del metal se puede apreciar que no se ha generado variación alguna del 2015 al 2017 -2 empresas activas en la provincia_-; en el sector madera en el periodo de estudio existe una empresa activa la cual abarca todo el mercado. Finalmente, en el sector de bebidas no alcohólicas del 2015 al 2017 no hay variación, 2 empresas activas. A 
través de este análisis en la figura 1 se puede evidenciar que el sector manufacturero ha ido decreciendo en número de oferentes en el área alimenticia.

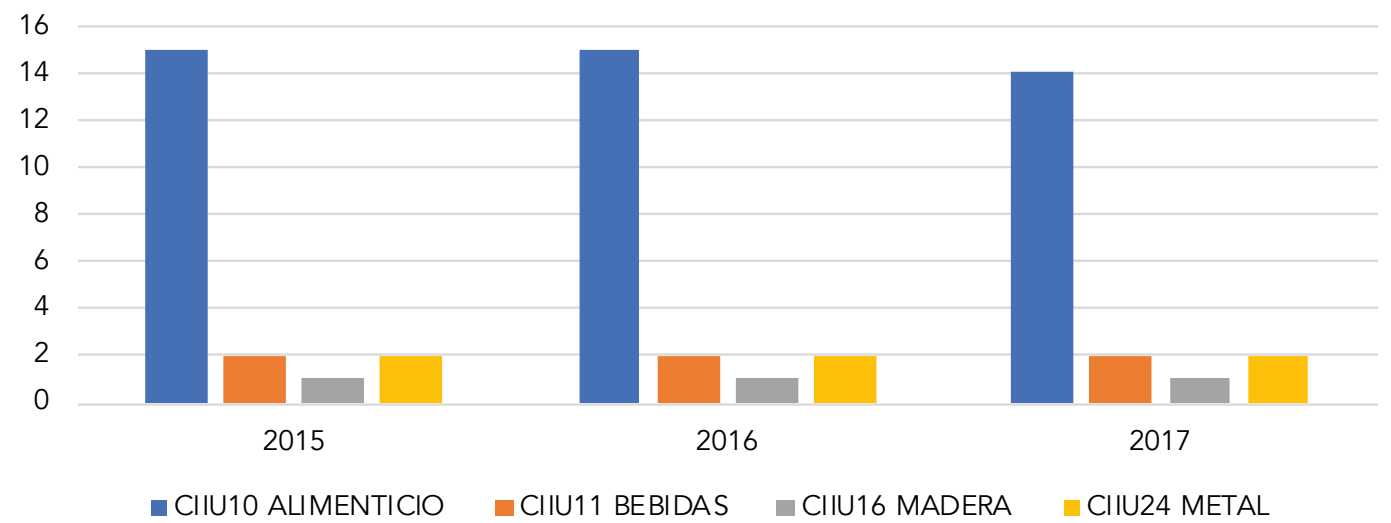

Figura 1. Evolución del número de compañías industriales en Cotopaxi

El sector industrial en la provincia de Cotopaxi ha tenido gran impacto en el campo de la metalmecánica, la alimentación y la madera, sectores que han estado presentes por más de 10 años y generado un sin número de fuentes de trabajo. Estos han traído consigo el desarrollo de la provincia, actualmente las empresas Novacero y Aglomerados Cotopaxi se han expandido a todo el territorio nacional e incluso tienen operaciones fuera del país. De acuerdo con su estructura económica, se evidencia crecimiento en los cuatro sectores (tabla 2).

Tabla 2. Crecimiento en la estructura económica del sector industrial de Cotopaxi

\begin{tabular}{lllll}
\hline Año & \multicolumn{1}{c}{ Sector } & \multicolumn{1}{c}{ Activo } & \multicolumn{1}{c}{ Pasivo } & \multicolumn{1}{c}{ Patrimonio } \\
\hline 2015 & Alimenticio & $\$ 28.741 .866,75$ & $\$ 14.090 .639,39$ & $\$ 14.651 .227,36$ \\
\hline 2015 & Metal & $\$ 288.547 .114,73$ & $\$ 168.751 .186,44$ & $\$ 119.795 .928,29$ \\
\hline 2015 & Bebidas & $\$ 11.892 .249,28$ & $\$ 9.237 .771,52$ & $\$ 2.654 .477,76$ \\
\hline 2015 & Madera & $\$ 84.908 .072,50$ & $\$ 23.120 .460,80$ & $\$ 61.787 .611,70$ \\
\hline 2016 & Alimenticio & $\$ 44.468 .834,95$ & $\$ 30.196 .580,96$ & $\$ 14.272 .253,99$ \\
\hline 2016 & Metal & $\$ 292.235 .327,09$ & $\$ 165.839 .652,06$ & $\$ 126.395 .675,03$ \\
\hline 2016 & Bebidas & $\$ 11.125 .318,40$ & $\$ 8.667 .829,66$ & $\$ 2.457 .488,74$ \\
\hline 2016 & Madera & $\$ 85.322 .377,80$ & $\$ 22.092 .792,40$ & $\$ 63.229 .585,40$ \\
\hline 2017 & Alimenticio & $\$ 36.907 .161,58$ & $\$ 22.212 .985,72$ & $\$ 14.694 .175,86$ \\
\hline 2017 & Metal & $\$ 328.269 .178,29$ & $\$ 193.024 .244,45$ & $\$ 135.244 .933,84$ \\
\hline 2017 & Bebidas & $\$ 12.986 .900,59$ & $\$ 10.495 .120,05$ & $\$ 2.491 .780,54$ \\
\hline 2017 & Madera & $\$ 91.496 .013,90$ & $\$ 26.693 .940,60$ & $\$ 64.802 .073,30$ \\
\hline
\end{tabular}

En el año 2015, el sector industrial alimenticio alcanzó alrededor de 28 millones en su activo y cerca de 14 millones en su pasivo y su patrimonio. En el transcurso de dos años 
su estructura financiera se incrementado así: 36 millones en su activo y 22 millones en su pasivo; el patrimonio se mantuvo igual (14 millones). Este crecimiento en el transcurso de los años 2015 a 2017 representa en el activo un 22\% y en el pasivo un 36\%. Con respecto al sector industrial del metal, en el 2015 alcanzó alrededor de 288 millones en su activo, cerca de 168 millones en su pasivo y 119 millones en su patrimonio. Para el año 2017 su estructura financiera muestra una concentración de 328 millones en su activo, 193 millones en su pasivo y cerca de 135 millones en su patrimonio. Este crecimiento durante dos años presenta una variación a razón del 13\% en el activo, 14\% en el pasivo y 13\% en el patrimonio. El sector industrial de bebidas en el 2015 alcanzó alrededor de 11 millones en su activo, 9 millones en su pasivo y 2 millones en su patrimonio, en el transcurso de dos años su estructura financiera se ha incrementado así: 12 millones en su activo y 10 millones en pasivo; el patrimonio se mantuvo igual; porcentualmente el incremento fue de $9 \%$ (activo) y $11 \%$ (pasivo).

En este análisis se puede apreciar que el sector del metal es el que más creció, mientras que el sector de bebidas es el que menos lo hizo en este periodo. El sector del metal comprende una actividad que desde varios años atrás se ha consolidado en la provincia de Cotopaxi y ha generado la mayor fuente de trabajo para la localidad. El sector de bebidas es un sector que también ha ido creciendo. En la tabla 3 se presenta cómo está constituido el sector en términos de ingresos contra costos y gastos; finalmente, se expone la utilidad económica que genera cada área del sector industrial manufacturero de la provincia de Cotopaxi.

Tabla 3. Monto de ingresos, costos, gastos y utilidad

\begin{tabular}{lllll}
\hline Año & \multicolumn{1}{c}{ Sector } & \multicolumn{1}{c}{ Ingresos } & \multicolumn{1}{c}{ Costos y gastos } & \multicolumn{1}{c}{ Utilidad } \\
\hline 2015 & Alimenticio & $\$ 55.131 .369,64$ & $\$ 54.760 .111,60$ & $\$ 244.128,57$ \\
\hline 2015 & Metal & $\$ 290.921 .906,31$ & $\$ 282.894 .527,54$ & $\$ 5.319 .481,97$ \\
\hline 2015 & Bebidas & $\$ 3.827 .107,66$ & $\$ 3.637 .011,87$ & $\$ 126.095,79$ \\
\hline 2015 & Madera & $\$ 44.337 .667,43$ & $\$ 41.109 .911,69$ & $\$ 2.139 .455,74$ \\
\hline 2016 & Alimenticio & $\$ 62.174 .690,09$ & $\$ 61.612 .001,89$ & $\$ 374.036,20$ \\
\hline 2016 & Metal & $\$ 260.493 .752,51$ & $\$ 249.052 .114,71$ & $\$ 7.585 .266,65$ \\
\hline 2016 & Bebidas & $\$ 4.363 .448,78$ & $\$ 3.972 .000,40$ & $\$ 259.933,06$ \\
\hline 2016 & Madera & $\$ 44.420 .457,45$ & $\$ 40.899 .074,65$ & $\$ 2.390 .546,45$ \\
\hline 2017 & Alimenticio & $\$ 57.915 .631,83$ & $\$ 57.372 .624,39$ & $\$ 360.167,59$ \\
\hline 2017 & Metal & $\$ 330.326 .183,04$ & $\$ 318.351 .426,04$ & $\$ 7.928 .566,02$ \\
\hline 2017 & Bebidas & $\$ 5.045 .270,53$ & $\$ 4.919 .350,52$ & $\$ 83.409,19$ \\
\hline 2017 & Madera & $\$ 45.429 .394,39$ & $\$ 43.819 .161,58$ & $\$ 1.063 .027,18$ \\
\hline
\end{tabular}


Los ingresos que se reportan en el sector manufacturero alimenticio tienen un rango entre 55 y alrededor de 60 millones de dólares; para el sector del metal los ingresos varían entre 290 y 340 millones de dólares; el sector de bebidas tiene ingresos entre 3 a 5 millones y el sector madera tiene ingresos que van de 44 a 46 millones de dólares. Los gastos para el sector alimenticio tienen un rango entre 54 y 57 millones, para el sector metal varían entre 282 mil y 318 millones de dólares; el sector de las bebidas tiene una variación de 3 a 5 millones y el sector la madera tiene una variación de 41 a 44 millones de dólares. Analizados los ingresos, costos y gastos por sector se obtiene que el sector alimenticio tiene una utilidad en el año 2015 de 244 mil dólares y en el año 2017 de 360 mil dólares aproximadamente, la utilidad del sector metal varía, entre 2015 y 2017, de 5 a 8 millones aproximadamente, el sector de las bebidas tiene una variación de 126 mil a 83 mil dólares y en el sector de la madera la utilidad varía entre 2 a 1 millón respectivamente.

\subsection{Análisis de la rentabilidad del sector}

\subsubsection{Rentabilidad neta del activo (ROA)}

Se trata del "indicador que mide la rentabilidad del capital invertido por los accionistas" (Pardo, Armas \& Chamba, 2017, p. 200). Como se puede ver en la figura 2.

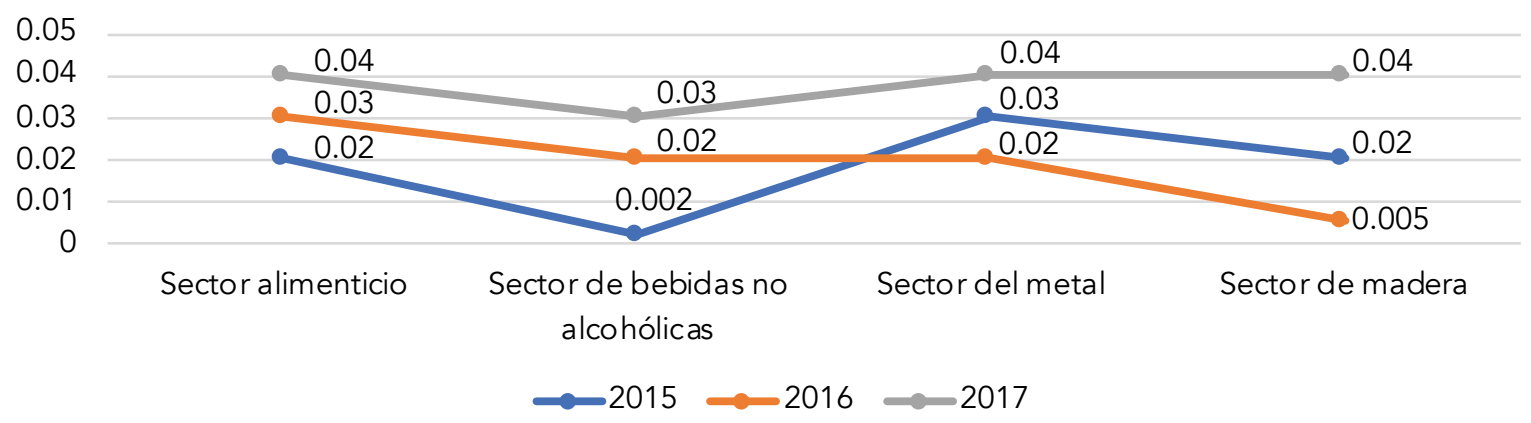

Figura 2. Rentabilidad neta del activo

Análisis e interpretación. Cuanto más elevado sea el rendimiento mejor, porque indicará que se obtiene más productividad del activo. Se menciona que, si el roA de una empresa es mayor a 5\%, esta es una buena empresa para invertir. En el sector alimenticio el activo ha ido paulatinamente creciendo, de un indicador de $2 \%$ ha pasado al $4 \%$ con un crecimiento constante, lo que es positivo, pues indica que la relación entre la utilidad 
neta y el activo total es positiva ya que proporciona rendimiento global sobre la inversión. En el sector de bebidas no alcohólicas se puede apreciar que el ROA del $0.2 \%$, en 2015, se incrementa al 3\%, en el 2017. Esto es muy positivo para el sector ya que indica que existe un rendimiento sobre la inversión generada. Para el sector de la fabricación de metal se puede apreciar un ROA variable: en el 2015 el indicador es del 3\%, en 2016 disminuye al 2\%. El sector de la madera presenta un roA que tiene variaciones significativas: en el año 2015, el roA fue de $2 \%$ para el 2016 fue de $0.5 \%$ y para el 2017 fue de 4\%; se aprecia que en el 2016 la empresa tuvo una rentabilidad mínima sobre sus activos lo que repercute en la rentabilidad del sector.

\subsubsection{Rentabilidad operacional del patrimonio (ROE)}

Es el "indicador que mide la rentabilidad del total de activos de la empresa" (Pardo, Armas \& Chamba, 2017, p. 200). Este se ilustra con la figura 3.

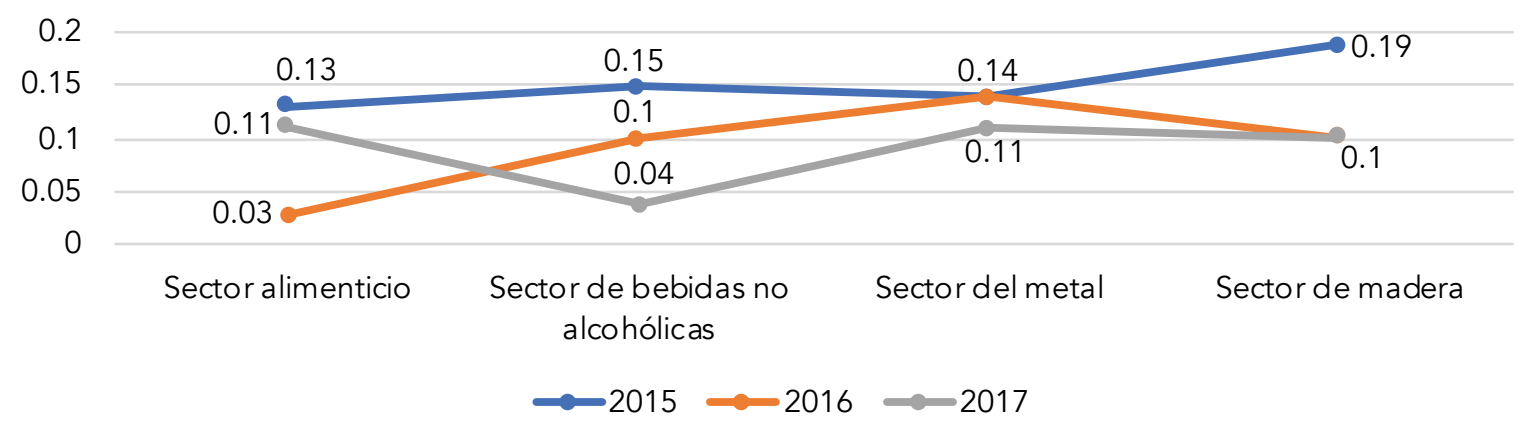

Figura 3. ROE sector industrial

Análisis e interpretación. Este indicador nos muestra la rentabilidad obtenida frente al patrimonio bruto. A medida que el valor del roe sea mayor, mejor será esta. En cualquier caso, como mínimo, ha de ser positiva y superior a las expectativas de los accionistas. En el sector alimentico se observan variaciones significativas: en el 2015 el roE fue del 13\%, en el 2016 bajó al 3\% y en el 2017 subió a 11\%; se observa que los resultados presentados en estos años muestran una tendencia lateral bajista lo que indica poca rentabilidad sobre el patrimonio neto, en especial en los últimos años. En el sector de bebidas no alcohólicas también hubo grandes variaciones: en el 2015 el roe fue del 15\%, en el 2016 bajó al 10\% y en el 2017 pasó a $4 \%$; se observa que los resultados presentados en estos años muestran una tendencia lateral bajista, que indica que la rentabilidad sobre el patrimonio neto no supera las expectativas del sector. En el sector de la fabricación del metal las variaciones fueron mínimas: en 2015 y 
2016 el roe fue del 14\% y en el 2017 bajó al 11\%; se observa que los resultados presentados en estos años muestran una tendencia a la baja lo que muestra que la rentabilidad sobre el patrimonio neto tiende a disminuir, producto de los diversos factores internos y externos del sector, como es la disminución en las ventas o por políticas gubernamentales que atraviesa el país. En el sector de la madera en el 2015 el roe fue del 19\% y en 2016 y 2017 bajó al 10\%; se observa que los resultados presentados en estos años muestran una tendencia lateral bajista lo que indica que la rentabilidad sobre el patrimonio neto decae, debido a las ventas y a factores externos como las políticas del gobierno.

\subsubsection{Rentabilidad sobre la inversión ROI}

Sr. autor, falta el llamado de la figura 4 en el texto

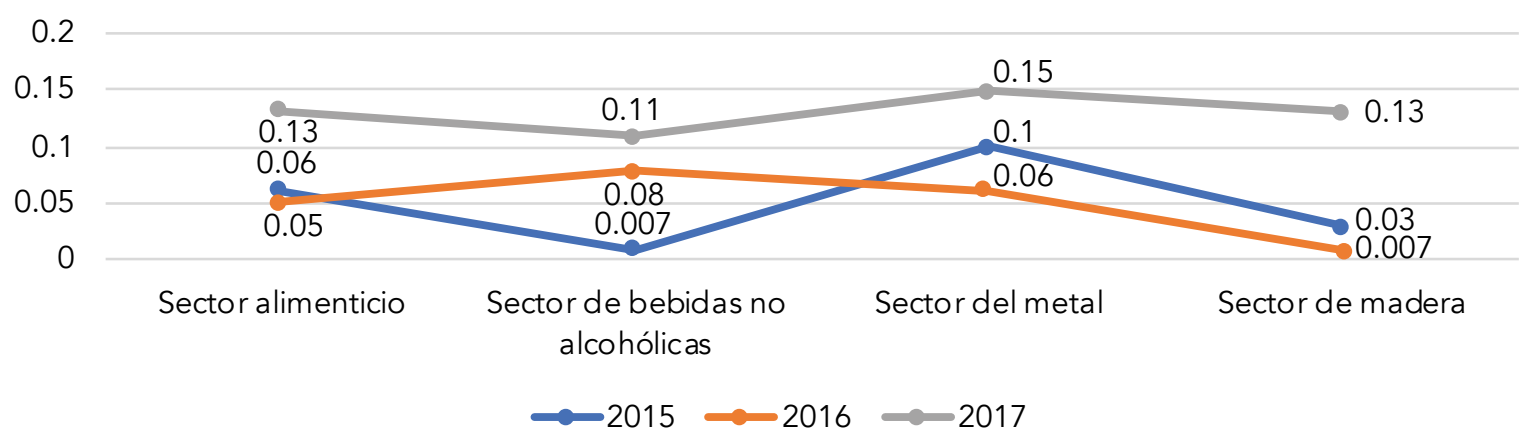

Figura 4. Rentabilidad operacional sobre la inversión roi sector industrial

Análisis e interpretación. El ror se utiliza para evaluar una empresa en marcha: si el ror es positivo significa que la empresa es rentable (mientras más alto sea el roI, más eficiente es la empresa al usar el capital para generar utilidades). Si el ror es menor o igual a cero, significa que los inversionistas están perdiendo dinero. El sector alimenticio ha tenido un crecimiento sostenido, de un indicador del 6\% en 2015 pasó, en 2017, a un indicador del 13\%. El sector de bebidas no alcohólicas también presenta un crecimiento sostenido en los periodos analizados, en el 2015 el sector presenta un indicador del $0.7 \%$, que en el 2017 alcanza el 11\%. El sector de fabricación de metal en los periodos analizados presenta un RoI con altibajos significativos, para el 2015 el indicador alcanza un 10\%, en el 2016 decrementa a un 6\% y en el 2017 sube al 15\% siendo, el resultado más alentador para el sector. Finalmente, el sector de la madera muestra un indicador ror con altibajos significativos: en el 2015 el indicador alcanza un 3\%, mientras que en el 2016 disminuye al $0.7 \%$ y para el 2017 incrementa a un 13\%, el resultado muy favorable para equilibrar los resultados operacionales del sector. 


\subsection{Análisis financiero de las empresas grandes del sector industrial de Cotopaxi}

Para poder determinar el modelo CAPM en el sector industrial de la provincia de Cotopaxi, es necesario realizar un análisis financiero y de las principales incidencias del sector a fin de poder determinar los factores más relevantes al momento de tomar una decisión (tabla 4).

Análisis e interpretación. Una vez analizados los indicadores financieros se puede mencionar que en promedio el sector dispone de indicadores de liquidez favorables. Sin embargo, hay que destacar que la empresa La Finca, durante el periodo analizado, carece de liquidez: al 2017 por cada dólar que la empresa tiene en sus pasivos dispone de 0.77 en sus activos. Para poder cancelar sus obligaciones a corto plazo, lo óptimo es tener una liquidez del 1.50; se observa que esta tiene una tendencia aleatoria. La empresa Aglomerados Cotopaxi es la que dispone de los fondos necesarios para cubrir sus obligaciones inmediatas. Con respecto al capital de trabajo, se observa que la empresa La Finca trabaja con capital de trabajo negativo lo que explica los indicadores de liquidez y la falta de recursos para poder cubrir necesidades a corto plazo.

Los indicadores de endeudamiento con relación al activo tienen como objetivo medir el nivel del activo total de la empresa financiado con recursos aportados a corto y largo plazo por los acreedores. En el caso de las empresa Novacero, Aglomerados Cotopaxi, Fuentes San Felipe y Molinos Poultier, estas están dentro de los parámetros establecidos: lo óptimo es que el $40 \%$ del activo total sea financiado por el pasivo total de la empresa, el resto se realiza por intermedio del patrimonio de la empresa. ${ }^{1}$ Por su parte, la empresa La Finca tiene un endeudamiento entere el 70 y el 85\% lo que es alarmante, ya que la empresa está trabajando en función del financiamiento de los acreedores. Con respecto al endeudamiento con relación al patrimonio se puede mencionar que las empresas Novacero, La Finca y Molinos Poultier son las que se han financiado en mayor proporción con el dinero de los acreedores, en el caso de la empresa La Finca por cada dólar que tiene en su patrimonio en el año 2017, 2.58 fue financiado por terceras personas.

Hay empresas que sobrepasan este parámetro, pero tomando en cuenta los flujos de efectivo que tienen están optimizando su gestión. 
Decisiones de inversión y rentabilidad bajo la valoración financiera en las empresas industriales grandes

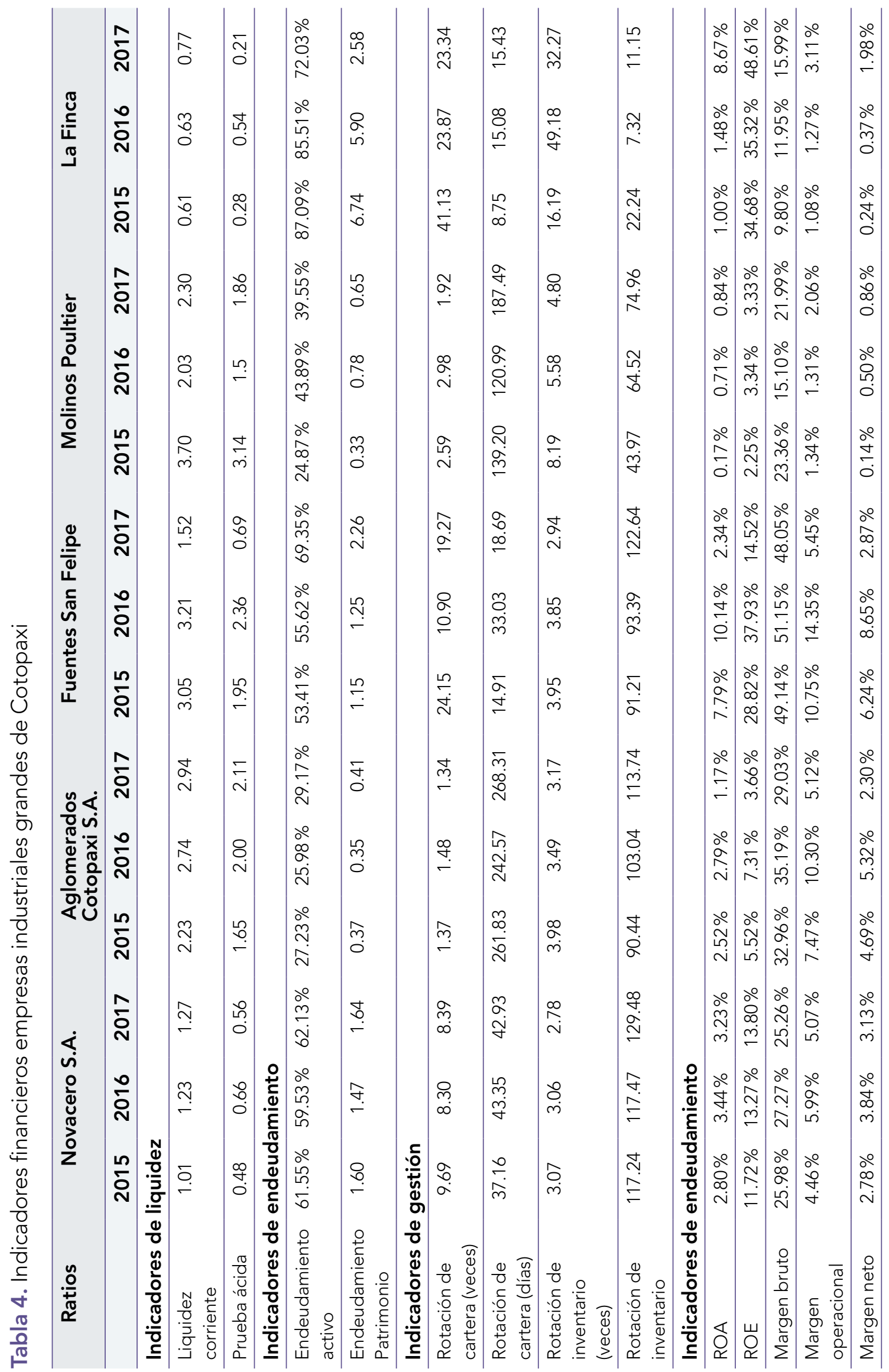


Los indicadores de actividad muestran que la cartera de la empresa rotó en el año 2015 10 veces en el año y se tardó en recuperar 37 días, mientras que para el 2016 la rotación fue más lenta, la cartera rotó 8 veces en el año y tardo 43 días en recuperar la cartera; para el año 2017, se repite la misma tendencia. Los inventarios, por su parte, para el año 2015, 2016 y 2017 tuvieron una rotación de 3 veces al año y se demoraron en venderlos 117 para el 2015 y 2016, y 129 días para el 2017. Las empresas que más tardan en recuperar su cartera son Aglomerados Cotopaxi y Molinos Poultier.

La empresa que tiene más eficiencia en la gestión de su cartera es Fuentes San Felipe. Los indicadores de rentabilidad del sector muestran un panorama que agrega valor, con respecto al ROA, el retorno que proporciona la inversión por cada dólar en su activo para el año 2015 es del 2.80\%, para el 2016, del 3.44\% y para el 2017, del 3.23\% -lo óptimo en toda empresa es un 5\%-; la empresa no está mal pero mejorando su gestión podría llegar a los parámetros óptimos. Con respecto al ROE, para el 2015 este presenta un 12\%, para el 2016 un 13\% y para el 2017 un 14\%. Un rOE que aumente constantemente generalmente indica que la empresa está haciendo un excelente trabajo en crear utilidades sin la necesidad de incrementar el financiamiento por parte de los accionistas.

\subsection{Determinación del modelo CAPM y valoración financiera}

Continuamos con el proceso donde se podrán observar las fluctuaciones de las rentabilidades mediante los factores de riesgo propuestos por los modelos de valoración (Cáceres, 2005). Para poder determinar la tasa de descuento es necesario conocer la tasa del costo de oportunidad de los accionistas para lo cual se utiliza el modelo CAPM. Ecuador es un país con un mercado de valores muy reducido, gran parte de las empresas no cotizan en la bolsa de valores, esto dificulta la obtención de información histórica para el cálculo de la tasa de riesgo de la industria, un componente de la fórmula tradicional de la tasa de costo de oportunidad de los accionistas. Por ello, el método CAPM tuvo ser adaptado para poder aplicarlo en este estudio.

Según lo plantea Sabal (2003), el modelo CAPm se puede adaptar a un método de practicidades, a través de la fórmula:

$$
E(R i x)=R f+\beta *[E(R m)-R f]+C R x
$$


La fórmula se entiende de la siguiente manera:

E(Rix): Rendimiento esperado del activo $i$ en el país $x$.

Rf: Tasa libre de riesgo.

B: Beta de una compañía similar en un país desarrollado.

$\mathbf{E}(\mathbf{R m})$ : Rendimiento esperado del mercado.

CRx: Riesgo país del país $x$ (generalmente se toma el spread entre un título de largo plazo emitido en dólares por el país $x$ y un us T-Bond de plazo similar).

Un aspecto sobre el modelo es que, en el capm tradicional, los resultados de la aplicación directa a economías emergentes proyectan sesgos significativos, debido a una baja correlación entre estos mercados y los de economía global (Zúñiga \& Soria, 2009). Para continuar con la determinación del rendimiento nominal de una empresa dedicada a la fabricación de productos a base de metal en Ecuador, se debe calcular primero el rendimiento nominal requerido en Estados Unidos, para esto es necesario desapalancar las betas de las dos empresas antes seleccionadas (fórmula 3). Según Ortiz (2016), "la beta apalancada es un indicador de riesgo que mide qué tan riesgoso puede ser un activo ante variaciones del mercado" (p. 11); mientras que "los rendimientos exigidos por un accionista apalancado son mayores que los de uno no apalancado" (Wong \& Chirinos, 2016, p. 71).

$$
\beta D=\frac{\beta A}{\left(1+\frac{D}{P}\right) *(1-T)}
$$

Donde:

BD: Beta desapalancada

BA: Beta apalancada

D: Deuda de la empresa

P: Capital social

T: Tasa impositiva.

Posteriormente se calcula el rendimiento requerido de una empresa dedicada a la fabricación de estructuras metálicas en Estados Unidos. Mediante la siguiente fórmula: 


$$
k_{U S A}=R f+\beta p(R m-R f)
$$

Según lo menciona Sabal (2003), antes de encontrar el rendimiento requerido de este tipo de negocio en Ecuador, se debe encontrar el rendimiento real del mismo, en Estados Unidos, considerando la inflación:

$$
K_{\text {Real USA }}=\left[\left(1+K_{U S A}\right) /\left(1+\text { Tasa de inflación }{ }_{U S A}\right)\right]-1
$$

Para calcular el rendimiento requerido de una empresa similar en Ecuador, se afecta el rendimiento real mínimo requerido en Estados Unidos por el riesgo país de Ecuador.

$$
K_{\text {Real Ecuador }}=\left[\left(1+K_{\text {Real USA }}\right) *\left(1+R p_{\text {Ecuador }}\right)\right]-1
$$

Por último, nominalmente se cuantifica el costo mínimo requerido con los siguientes cálculos:

$$
K_{\text {Nominal Ecuador }}=\left[\left(1+K_{\text {Real Ecuador }}\right) *(1+\text { Tasa de inflación } \text { Ecuador })\right]-1
$$

Una vez determinado el modelo CAPM se procede a realizar la valoración financiera por cada empresa en estudio a fin de conocer su valor en el mercado y las determinantes necesarias que permitan al inversionista tomar la mejor decisión, cabe mencionar que es muy importante el criterio de los inversionistas antes de invertir en una empresa ya que de ello dependerá la rentabilidad que genere dicha decisión y el impacto en los recursos monetarios de las organizaciones. Grande (2018) añade que el mercado no va a recompensar a inversores que se exhiban a cualquier riesgo, si no solo a quienes han conseguido armar una cartera óptima en los términos de este modelo. Se debe tener en consideración que "el inversionista escoge un portafolio de inversiones con base en dos aspectos esenciales: la tasa de retorno esperada y la volatilidad" (Santana, 2013, p. 734). Ante eso, Ariza y Cadena (2013) aclaran que "los activos más volátiles tendrán betas superiores a la unidad (su rendimiento subirá y bajará más rápidamente que el del mercado), mientras que los menos volátiles tendrán betas menores que la unidad (su rendimiento subirá y bajará más lentamente)” (p. 231).

Cada empresa cuenta con factores internos y externos que determinan la estructura de capital como la oferta, la demanda y la composición del activo, el pasivo y el patrimonio, 
así como nivel de ventas, gastos y utilidades, que están determinados por otros factores macroeconómicos como el riesgo país, la inflación, etc. "Las empresas con una estructura de capital eficiente aseguran una óptima distribución de los activos operacionales, con lo cual reducen el riesgo de liquidez y otorgan beneficios financieros adicionales medidos a través del aumento de la rentabilidad de los activos" (Carmona \& Chaves, 2015, p. 50-51).

A continuación, se presenta un análisis comparativo de los resultados obtenidos en la tabla 5.

Tabla 5. Análisis comparativo inversión vs. rentabilidad

\begin{tabular}{|c|c|c|c|c|c|c|c|c|}
\hline Empresa & Año & Inversión & Rentabilidad & WACC & CAPM & $\mathrm{Va}$ & $\begin{array}{l}\text { Valor } \\
\text { empresa }\end{array}$ & TIR \\
\hline \multirow[t]{3}{*}{ Novacero } & 2017 & $\$ 252.833 .366,38$ & $\$ 13.213 .357,54$ & \multirow[t]{3}{*}{$16.24 \%$} & \multirow[t]{3}{*}{$29.30 \%$} & \multirow[t]{3}{*}{$\$ 814.892 .697,41$} & \multirow[t]{3}{*}{$\$ 562.059 .331,03$} & \multirow[t]{3}{*}{$43 \%$} \\
\hline & 2016 & $\$ 224.788 .919,54$ & $\$ 12.073 .476,40$ & & & & & \\
\hline & 2015 & $\$ 218.683 .090,27$ & $\$ 9.854 .600,11$ & & & & & \\
\hline \multirow{3}{*}{$\begin{array}{l}\text { Aglomerados } \\
\text { Cotopaxi }\end{array}$} & 2017 & $\$ 91.175 .504,53$ & $\$ 2.363 .628,17$ & \multirow[t]{3}{*}{$16.88 \%$} & \multirow[t]{3}{*}{$19.87 \%$} & \multirow[t]{3}{*}{$\$ 211.585 .629,06$} & \multirow[t]{3}{*}{$\$ 120.410 .124,53$} & \multirow[t]{3}{*}{$22 \%$} \\
\hline & 2016 & $\$ 85.558 .702,88$ & $\$ 4.629 .667,11$ & & & & & \\
\hline & 2015 & $\$ 84.908 .072,50$ & $\$ 3.410 .676,17$ & & & & & \\
\hline \multirow{3}{*}{$\begin{array}{l}\text { Fuentes San } \\
\text { Felipe }\end{array}$} & 2017 & $\$ 2.094 .666,29$ & $\$ 93.230,82$ & \multirow[t]{3}{*}{$9.28 \%$} & \multirow[t]{3}{*}{$12.62 \%$} & \multirow[t]{3}{*}{$\$ 3.926 .423,27$} & \multirow[t]{3}{*}{$\$ 1.831 .756,98$} & \multirow[t]{3}{*}{$15 \%$} \\
\hline & 2016 & $\$ 1.447 .409,71$ & $\$ 243.641,72$ & & & & & \\
\hline & 2015 & $\$ 1.277 .065,28$ & $\$ 171.460,69$ & & & & & \\
\hline \multirow{3}{*}{$\begin{array}{l}\text { Molinos } \\
\text { Poultier }\end{array}$} & 2017 & $\$ 13.644 .495,49$ & $\$ 274.642,06$ & \multirow[t]{3}{*}{$13.39 \%$} & \multirow[t]{3}{*}{$14.10 \%$} & \multirow[t]{3}{*}{$\$ 37.274 .501,13$} & \multirow[t]{3}{*}{$\$ 23.630 .005,64$} & \multirow[t]{3}{*}{$29 \%$} \\
\hline & 2016 & $\$ 14.493 .283,30$ & $\$ 271.632,70$ & & & & & \\
\hline & 2015 & $\$ 10.688 .727,39$ & $\$ 180.677,41$ & & & & & \\
\hline \multirow[t]{3}{*}{ La Finca } & 2017 & $\$ 756.767,41$ & $\$ 102.879,71$ & \multirow[t]{3}{*}{$11.27 \%$} & \multirow[t]{3}{*}{$13.72 \%$} & \multirow[t]{3}{*}{$\$ 1.051 .859,32$} & \multirow[t]{3}{*}{$\$ 295.091,91$} & \multirow[t]{3}{*}{$8 \%$} \\
\hline & 2016 & $\$ 852.431,36$ & $\$ 43.637,57$ & & & & & \\
\hline & 2015 & $\$ 859.304,93$ & $\$ 38.478,55$ & & & & & \\
\hline
\end{tabular}

\section{Discusión}

Como medio de verificación del presente estudio investigativo se utilizó la prueba de los rangos con signo de Wilcoxon, esta es una prueba no paramétrica para comparar la media de dos muestras relacionadas y determinar si existen diferencias entre ellas. Se utiliza como alternativa a la prueba $t$ de Student cuando no se puede suponer la normalidad de dichas muestras. Debe su nombre a Frank Wilcoxon, quien la publicó en 1945. Se utiliza 
cuando la variable subyacente es continua pero no se presupone ningún tipo de distribución particular (Farfán, 2014, p. 70)

Es necesario comparar dos muestras independientes que no se puedan reducir a un conjunto único de datos, ya que pueden contener diferentes números de mediciones. Existen varias pruebas no paramétricas que permiten abordar estas situaciones (Miller \& Miller, 1993).

Según lo menciona Pria (2003), sean A y B dos muestras con M y N observaciones respectivamente, donde se cumple que $\mathrm{M} \geq \mathrm{N}$, la prueba de suma de rangos de Wilcoxon para determinar si ambas muestras proceden de la misma distribución es

1. Ordenar todas las observaciones de ambas muestras como si fuera una sola, en orden ascendente y asignar los rangos a los valores ordenados.

2. Identificar los valores que pertenecen a cada muestra.

3. Determinar el estadígrafo que en esta prueba es To = Suma de rangos de $\mathrm{B}=\left(\sum\right.$ rangos $\left.\mathrm{B}\right)$ —en donde $\mathrm{B}$ es la muestra más pequeña-

La regla de decisión será plantear la Hipótesis que se adecúe a la situación que se necesita resolver, y aplicar la regla de decisión (tabla 6).

Tabla 6. Aplicación de la regla de decisión para la prueba de Wilcoxon

\begin{tabular}{lcl}
\multicolumn{1}{c}{ Hipótesis } & $\begin{array}{c}\text { Regla de decisión } \\
\text { rechazar } \mathrm{H}_{0} \text { si }\end{array}$ & $\boldsymbol{\alpha}$ más usados \\
\hline$H 0: M_{e B}=M_{e A}$ & $T_{0} \leq T_{1}$ & 0.025 \\
$H 1: M_{e B} \neq M_{e A}$ & $T_{0} \geq T_{S}$ & 0.05 \\
\hline$H 0: M_{e B} \geq M_{e A}$ & $T_{0} \leq T_{1}$ & 0.05 \\
$H 1: M_{e B}<M_{e A}$ & & 0.01 \\
\hline$H 0: M_{e B} \leq M_{e A}$ & $T_{0} \geq T_{S}$ & 0.05 \\
$H 1: M_{e B}>M_{e A}$ & & 0.01 \\
\hline
\end{tabular}

Fuente: Pria (2003).

Donde ті у тs son los valores obtenidos en la tabla de valores críticos para la estadística de prueba de la suma de rangos de Wilcoxon, considerando un tamaño de NA y NB y un 
nivel de significación dado. Esta tabla sirve para trabajar cuando el tamaño de la muestra menor llega hasta 25 y la mayor a 50. MeB y MeA representan los parámetros de tendencia central de las distribuciones de ambas muestras. Cuando el tamaño de la muestra menor excede las 25 observaciones puede trabajarse con la aproximación a la distribución normal (Pria, 2003).

Otra forma de rechazar la hipótesis nula es cuando se está trabajando con un programa estadístico que calcule To y p que es la probabilidad de error de tipo I asociada a ese valor. En este caso, si el valor de $p$ es menor que el $\alpha$ prefijado, se rechaza la hipótesis nula.

\subsection{Descripción}

Para poder desarrollar la prueba de Wilcoxon se consideran 2 muestras significativas con la información obtenida de acuerdo con el análisis financiero del 2015 al 2017 de las empresas del sector manufacturero de la provincia de Cotopaxi sobre las dos variables de estudio (tabla 7).

Tabla7. Datos de las variables en estudio

\begin{tabular}{lccl}
\hline \multicolumn{1}{c}{ Empresa } & Año & Inversión & Rentabilidad \\
\hline Novacero & 2017 & $\$ 252.833 .366,38$ & $\$ 13.213 .357,54$ \\
\cline { 2 - 4 } & 2016 & $\$ 224.788 .919,54$ & $\$ 12.073 .476,40$ \\
\cline { 2 - 4 } & 2015 & $\$ 218.683 .090,27$ & $\$ 9.854 .600,11$ \\
\hline Aglomerados Cotopaxi & 2017 & $\$ 91.175 .504,53$ & $\$ 2.363 .628,17$ \\
\cline { 2 - 4 } & 2016 & $\$ 85.558 .702,88$ & $\$ 4.629 .667,11$ \\
\hline Fuentes San Felipe & 2015 & $\$ 84.908 .072,50$ & $\$ 3.410 .676,17$ \\
\hline Molinos Poultier & 2017 & $\$ 2.094 .666,29$ & $\$ 93.230,82$ \\
\hline & 2016 & $\$ 1.447 .409,71$ & $\$ 243.641,72$ \\
\hline La Finca & 2015 & $\$ 1.277 .065,28$ & $\$ 171.460,69$ \\
\hline & 2016 & $\$ 13.644 .495,49$ & $\$ 274.642,06$ \\
\hline & 2015 & $\$ 10.688 .283 .727,39$ & $\$ 180.677,41$ \\
\hline & 2017 & $\$ 756.767,41$ & $\$ 102.879,71$ \\
\hline
\end{tabular}


Una vez obtenidos los datos se procede a ingresar los datos al sistema spss Management para realizar la comprobación de la hipótesis del presente estudio. Se observa la tabla de Wilcoxon y busca un valor de significación de 0.05, ya que el nivel de confiabilidad es del 95\%. En este caso, en dicha tabla solo existe el rango de la muestra hasta 15 por lo que se aplica la siguiente fórmula:

\section{Muestras pequeñas:}

S+ (Suma de rangos de las diferencias positivas entre los datos)

\section{Muestras grandes:}

$$
Z=\frac{S_{+}-n(n+1) / 4}{\sqrt{n(n+1)(2 n+1) / 24}}
$$

Donde:

S+ = Suma de rangos de las diferencias positivas entre los datos $\mathbf{n}=$ número de la muestra

De este modo se destacan "las diferencias entre los rendimientos de las empresas grandes y pequeñas" (Padrón \& García, 2006, p. 202). En el caso del presente estudio se utiliza la metodología para muestras pequeñas (tabla 8).

Tabla 8. Comprobación de la hipótesis

\begin{tabular}{lccc}
\hline \multicolumn{4}{c}{ Estadísticos de prueba } \\
\hline & R2017 - I2017 & R2016 - I2016 & R2015 - I2015 \\
\hline$Z$ & $-2.023^{b}$ & $-2.023^{b}$ & $-2.023^{b}$ \\
\hline Sig. asintótica (bilateral) & .043 & .043 & .043 \\
\hline \begin{tabular}{l} 
a. Prueba de rangos con signo de Wilcoxon \\
\hline
\end{tabular} \\
\hline
\end{tabular}

Al verificar la hipótesis de que una variable tenga relación con la otra, en este caso la inversión y la rentabilidad de los tres años en estudio, se utiliza el estadístico de Wilcoxon para pruebas no paramétricas. El estadístico de Wilcoxon recoge parejas, en este estudio, 
la inversión y rentabilidad, la cual contrasta la hipótesis. Se corrió el programa spss y consideró la referencia estadística cuando el valor $p$ o la significancia menor a 0.05 con lo que se rechaza la hipótesis nula y se acepta la hipótesis alternativa (tabla 8), o cuando el valor de $Z$ es superior a 2 positivo o inferior a -2 .

En este caso, se comprueba la hipótesis alternativa en los tres años de estudio porque el valor de la significancia es menor que 0.05; por tanto, las decisiones de inversión inciden en la rentabilidad de las empresas del sector industrial manufacturero de la provincia de Cotopaxi.

La prueba estadística que se realiza es comprobable con un 95\% de nivel de confianza, se tiene la certeza que el $95 \%$ de la hipótesis alterna se lleve a cabo con un nivel de significación del 5\%.

\section{Conclusiones}

La estructura de financiamiento que presenta el sector tiende a apalancarse con recursos provenientes de terceros, la empresa La Finca muestra un mayor porcentaje de recursos ajenos con un $81.54 \%$ que principalmente proviene de recursos de sus socios, proveedores y otros pasivos. Mientras que la empresa que menos recursos de terceros utiliza es Aglomerados Cotopaxi con un $\mathbf{2 7 . 4 6 \% . ~ E l ~ s e c t o r ~ s e ~ a p a l a n c a ~ e n ~ g r a n ~ m e d i d a ~ d e ~ s u s ~ p r o v e e - ~}$ dores por lo que se puede mencionar que realizan una gran gestión, ya que están evitando costos generados de deuda financiera. Este mismo financiamiento, según el análisis, se está invirtiendo en gran medida en los activos fijos como maquinaria e infraestructura. Novacero y Aglomerados Cotopaxi son las empresas con más inversión en maquinaria, mientras que Fuentes San Felipe, Molinos Poultier y La Finca, en nueva infraestructura.

Cuatro de las cinco empresas analizadas presenta indicadores de liquidez positivos (>1), el más alto es el de la empresa Molinos Poultier con 2.68, seguida por Aglomerados Cotopaxi con 2.64, Fuentes San Felipe con 2.59 y Novacero 1.17 en promedio. Sin embargo, la empresa La Finca presenta indicadores de liquidez que no son alentadores para el 
sector, 0.67 en promedio. Globalmente estos resultados muestran que el sector presenta una referencia de disponer de una buena capacidad de pago frente a sus obligaciones con terceras personas. Según los datos expuestos la mejor empresa para invertir es Novacero, debido a que presenta indicadores financieros dentro de los parámetros establecidos, su liquidez de $1.17 \%$ está en los parámetros aceptables por un inversionista; además, tiene una buena gestión de su endeudamiento y cuenta con una buena rotación de cartera e inventarios. Al realizar su valoración con un horizonte de 5 años, se determinó un valor de $\$ 562.059 .331,03$ con una tasa interna de retorno del $43 \%$, considerando el costo promedio de capital (wacc) que corresponde al costo promedio de capital ponderado; es decir, que teniendo en cuenta la estructura de financiación de la empresa con deuda y con patrimonio esta está obteniendo el 16.24\%. Las otras empresas son también muy buenas alternativas de inversión; sin embargo, es necesario mejorar la gestión de su liquidez ya que hay gran cantidad de recursos monetarios sin invertir, es dinero ocioso que las empresas podrían utilizar para expandirse hacia nuevos mercados.

A través del estadístico de Wilcoxon se pudo determinar la relación directa de la rentabilidad y su efecto en las decisiones de inversión, se pudo determinar que el éxito de las empresas analizadas es la inversión que realizan en los activos fijos y en la infraestructura, acompañadas de una eficiente gestión en las ventas y la recuperación de cartera, inventarios y proveedores.

\section{Referencias}

Ariza Garzón, M., \& Cadena Lozano, J. (2013). Selección de portafolios de renta variable: Una propuesta a través de betas al alza y a la baja en el mercado colombiano. Criterio Libre, 11(19), 226-240. https://doi.org/10.18041/1900-0642/criteriolibre.2013v11n19.1109

Betancourt, K., García, C., \& Lozano, V. (2013). Teoría de Markowitz con metodología ewma para la toma de decision sobre cómo invertir su dinero. Atlantic Review of Economics, 1(1), 1-21.

Cáceres, R. (2005). El riesgo beta y la valoración de activos financieros en el mercado brusátil español. Estudios de Economía Aplicada, 23(1), 1-4. 
Canales, R. (2015). Criterios para la toma de decisión de inversiones. Revista Electrónica de Investigación en Ciencias Económicas, 3(5)101-117. https://doi.org/10.5377/reice. v3i5.2022

Carmona, D., \& Chaves, J. (2015). Factoring: una alternativa de financiamiento como herramienta de apoyo para las empresas de transporte de carga terrestre en Bogotá. Finanzas y Política Económica, 7(1), 27-53. Recuperado de http://www.scielo.org.co/pdf/fype/ v7n1/v7n1a02.pdf

Ccaccya, D. (2015). Analisis de rentabilidad de una empresa. Actualidad empresarial. Recuperado de http://aempresarial.com/servicios/revista/341_9_KAQKIKGSKPBXJ OWNCBAWUTXOEZPINLAYMRJUCPNMEPJODGCGHC.pdf

Cervantes, T., Villalba, S., \& Carmona, E. (2013). Aplicación del modelo CAPM y D-CAPM en las emprsas que han conformado el IPC en periodicos de crisis para la medicion del riesgo sistematico. Recuperado de https://www.researchgate.net/publication/269758691_aplicacion_del_modelo_capm_y_dcapm_en_las_empresas_que_han_conformado_el_ipc_en_periodos_de_crisis_para_la_medicion_del_riesgo_sistematico

Contreras, C., \& Cartes, F. (2012). Contraste empírico del CAPM en el mercado accionario chileno. Ingeniare: Revista Chilena de Ingeniería, 20(2), 255-266. https://doi.org/10.4067/ S0718-33052012000200012

Contreras, O., Bronfman, R., \& Arenas, C. (2015). Estrategia de inversión optimizando la relación rentabilidad-riesgo: evidencia en el mercado accionario colombiano. Estudios Gerenciales, 31(137), 383-392. https://doi.org/.1016/j.estger.2015.07.005

Costa de García, C. (febrero, 2018). Industria manufacturera:el sector de mayor aprte al PIB. Ekos Negocio, 286, pp. 56-58.

Farfán, J. (11 de noviembre de 2014). Estadística en la investigación. Recuperado de https:// es.scribd.com/document/246193700/LIBRO-DE-ESTADISTICA-2014-docx

Ferruz, L., Vargas, M., \& Nievas, J. (2008). ¿Utilizan los gestores españoles de fondos de inversión información privada en sus labores de gestión? Estudios de Economía Aplicada, 26(3), 257-278. Recuperado de https://www.redalyc.org/pdf/301/30113182012.pdf

Gallardo, J. (2012). Administracion estrategica de la visión a la ejecución. México D.F.: Alfaomega. Recuperado de https://es.scribd.com/document/372583436/GALLARDOAdministracion-Estrategica-de-La-Vision-a-La-Ejecucion-2012

Gallardo, J., Silvestri, K., Hernández, R., \& Romero, F. (2010). Planificación estratégica, una herramienta para la toma de decisiones en las gerencias medias del sector petrolero del estado Zulia. Revista de Formación Gerencial, 9(1), 200-226. 
García, Y. (2005). Análisis de los planes de pensiones del sistema individual en España a través de modelos de valoración de activos financieros. Estudios de Economía Aplicada, 1-4.

Garrison, R. (2012). La alquimia del apalancamiento. La Reserva Federal y las finanzas modernas. Procesos de Mercado, 9(2), 473-500. Recuperado de https://search.proquest.com/ openview/d29421cc78293f17c94409056b4433d5/1?pq-origsite=gscholar\&cbl=686495

Grande, D. (2018). El CAPM y su aplicación a países emergentes. (Tesis de maestría, Universidad Nacional de Rosario).

Guaman, J., \& Bravo, S. (2014). Plan plurianual de candidatura. Recuperado de https://www. cotopaxi.gob.ec/images/Documentos/PLAN-LISTAS-15-18-CNE.pdf

Guerrero, É. (2008). El modelo de valuación de activos de capital aplicado a mercados financieros emergentes. El caso de México 1997-2006. Contaduría y Administración, (226), 93-111. Recuperado de http://www.scielo.org.mx/pdf/cya/n226/n226a6.pdf

Herrera, M. (2014). Aula de economia. Recuperado de https://slideplayer.es/slide/26418/

Horna, L., Guachamín, M., \& Osorio, N. (2009). Análisis de mercado del sector industrias manufactureras en basea ciru 3 bajo un enfoque de concentración económica en el período 2000-2008 en el Ecuador. Revista Politecnica, (30), 230-243.

Instituto Nacional de Estadistica y Censo. (01 de Marzo de 2018). Boletin Tecnico de la Produccion de la Industria Manufacturera. Recuperad de http://www.ecuadorencifras.gob.ec/documentos/web-inec/Estadisticas_Economicas/IPI-M/2018/Marzo-2018/ BOLETIN_TECNICO_IPI_M_2018_03.pdf

Izquierdo, J. (2016). Crecimiento y rentabilidad empresarial en el sector industrial brasileño. Contaduría y Administración, 61(2), 266-282. https://doi.org/10.1016/j.cya.2015.12.001

Lizarzaburu, E., \& del Brio, J. (2016). Responsabilidad social corporativa y reputación corporativa en el sector financiero depaises en desarrollo. Revista de Globalización, Competitividad y Gobernabilidad, 10(1), 42-65. Recuperado de https://search.proquest. com/docview/1787709576/fulltextPDF/FBFC335E9D94C28PQ/1?accountid=36765

Londoño, C., \& Yaneth, C. (2011). Modelos de precios de los activos: un ejercicio comparativo basado en redes neuronales aplicado al mercado de valores colombiano. Lecturas de Economía, (75), 59-87. Recuperado de http://www.scielo.org.co/pdf/le/n75/n75a4.pdf

Manotas, D., \& Toro, H. (2009). Análisis de decisiones de inversión utilizando el criterio valor presente neto en riesgo (vPN en riesgo). Revista Facultad de Ingenieria de la Universidad de Antioquia, (49), 199-213. Recuperado de https://www.redalyc.org/pdf/430/43019324020. pdf 
(a) Marcelo, J., Quirós, M., \& Quirós, J. (2007). Análisis media-semivarianza: Una aplicación a las primas de riesgo en el mercado de valores Español. Estudios de Economía Aplicada, 25(1), 199-214. Recuperado de https://www.redalyc.org/articulo.oa?id=30113183008

(b)Marcelo, J., Quirós, M., \& Quirós, J. (2007). Modelos de valoracion de activos financieos con riesgo asimétrico. Revista Española de Financiación y Contabilidad, 36(136), 791-807.

Marcelo, J., Quirós, M., \& Quirós, J. (2013). Estructura financiera de la empresa y valoración de activos en el mercado bursátil español. Revista Española de Financiación y Contabilidad, 42(160), 561-589.

Martínez, C., Ledesma, J., \& Russo, A. (2013). Particularidades del modelo de fijación de precios de activos de capital (CAPM) en Mercados Emergentes. Análisis Financiero, (121), 37-47.

Miller, J., \& Miller, J. (1993). Estadística para quimica analítica. Wilmington: Addison, Wesley Iberoamericana.

Muhammad, A., \& Mohsin, R. (2015). Probability of return under camp: An empirical study of the interest margin. Journal of Statistics, 2(1), 58-76. Recuperado de https://search.proquest. com/openview/fc2e5ad4605891d87f29d916039babb3/1?pq-origsite=gscholar\&cbl=616526

Murillo, M., Peña, F., \& León, Ó. (2017). Optimización de portafolio de proyectos a través de la aplicación de programación lineal y el caPM. Revista Ciencias Estrategicas, 25(37), 71-86.

Ortiz, J. (2001). La valoración de empresas. Semestre Económico, 4(8), 1-13. Recuperado de https://revistas.udem.edu.co/index.php/economico/article/view/1394

Pabón, J. B. (2015). Valor económico agregado en las empresas del sector industrial manufacturero de Cúcuta periodo 2008-2012. Respuestas, 20(2), 54-72.

Padrón, Y., \& García, J. (2006). Revisión bibliográfica de la evidencia empírica de los modelos multifactoriales de valoración de activos financieros. Cuadernos de Economía, 25(44), 197-224.

Pardo, M., Armas, R., \& Chamba, L. (2017). Valoración del capital intelectual y su impacto en la rentabilidad financiera en empresas del sector industrial del Ecuador. Revista Publicando, 4(13-1), 193-206. Recuperado de https://revistapublicando.org/revista/index.php/crv/ article/view/785

Pria, M. (10 de Enero de 2003). Metodos no parametricos. Recuperado de http://www. Vcl. sld.cy/75 cm/facmedic/ webosalud/materiales/mnoparam.html

Puerta, F., Vergara, J., \& Huertas, N. (2018). Análisis financiero: enfoques en su evolución. Criterio Libre, 16(28), 75-94. https://doi.org/10.18041/1900-0642/criteriolibre.2018v16n28.2125

Rivera, V. (28 de Abril de 2013). Prezi Sector Manufacturero en America Latina. Recuperado de https://prezi.com/2j6sfmrymji3/sector-manufacturero-en-america-latina/ 
Romero, Y., \& Barrientos, L. (2013). Selección de carteras: una mirada a las metodologías estudiadas y aplicadas en Colombia. Contaduria Universidad de Antioquia, (63), 69-84. Recuperado de https://revistas.udea.edu.co/index.php/cont/article/view/24099/19724

Sabal, J. (2003). The discount rate in emerging markets: A guide. Barcelona: ESADE.

Santana, F. (2013). Modelo de valoración de activos financieros (CAPM) y teoría de valoración por arbitraje (APT): Un test empírico en las empresas del sector eléctrico brasileño. Cuadernos de Contabilidad, 14(35), 731-746. Recuperado de http://www.scielo.org.co/pdf/cuco/ v14n35/v14n35a14.pdf

Santibañez, J., Alcañiz, L., \& Gómez, F. (2014). Alternativa a la formulación clásica para el proceso de betas apalancadas: una aplicación al caso español. Boletín de Estudios Económicos, 69(212), 329-356.

Sierra, V., \& López, J. (2014). Análisis del impacto del tamaño de los activos en la cuenta de resultados mediante la utilización de espacios de fase y análisis de recurrencia. Contaduría Universidad de Antioquia, (65), 69-103. Recuperado de https://revistas.udea.edu.co/index. $\mathrm{php} / \mathrm{cont} / \mathrm{article} / \mathrm{view} / 24392 / 19913$

Velez, I. (2003). Análisis de portafolio. Grupo Consultor CaV Capital Advisory E Valuation, 1-54.

Veloz, M. (2015). El riesgo sistemático en la valoración de activos financieros de las principales compañías societarias que negocian en la bolsa de valores de Quito. (Tesis de maestría, Universidad Tecnica de Ambato, Ambato). Recuperado de http://repositorio.uta.edu.ec/ bitstream/123456789/20351/1/T3392M.pdf

Viloria, L. (2015). Estimación del beta para el sector inmobiliario a partir del desempeño de fondos de inversión inmobiliaria en Colombia. Finanzas y Política Económica, 7(1), 8395. https://doi.org/10.14718/revfinanzpolitecon.2015.7.1.4

Wong, D., \& Chirinos, M. (2016). ¿Los modelos basados en el CAPM valoran adecuadamente los emprendimientos familiares? Innovar, 26(61), 65-82. Recuperado de https://www.redalyc. org/jatsRepo/818/81846217005/html/index.html

Zúñiga, S., \& Soria, K. (2009). Costo del capital en el sector pesquero-acuícola chileno. Interciencia, 34(8), 543-550. 